\title{
La galería decimonónica del Cabezo de la Jara. Características constructivas e hidrogeológicas (Huércal Overa, Almería)
}

\author{
Antonio González Ramón ${ }^{(1,2)}$, Francisco García Granados ${ }^{(3)}$, Andrés Segura Herrero ${ }^{(2)}$, \\ Tomás J. Sánchez Díaz ${ }^{(2)}$, Diego Raul Gea López D.R. ${ }^{(2)}$, Joaquín Llamas Sánchez ${ }^{(2)}$, \\ Vanessa García Benzal(2), Alfonso Mazón Núñez ${ }^{(2)}$, Pedro Pérez Martínez ${ }^{(2)}$ \\ (1) Instituto Geológico y Minero de España, UnidadTerritorial de Granada. \\ Urb. Alcázar del Genil, 4-Edif. Zulema, 18006 Granada, España \\ (2) Asociación Espeleológica Velezana. C/ Levante, 1. Vélez Rubio, Almería, España. \\ (3) Comunidad de Regantes Aguas del Cabezo. Paraje las Labores, $n^{\circ}$. 44. C.P. 04691. Huércal-Overa, Almería, España \\ antonio.gonzalez@igme.es; aguasdelcabezo@hotmail.com; espeleovelez@gmail.com
}

\section{RESUMEN}

Entre 1864 y 1886 se construyó una galería para la captación de aguas subterráneas en el término municipal de Huércal Overa, perteneciente al acuífero del Cabezo de la Jara. Tiene una longitud original de más de $2 \mathrm{~km}$ y atraviesa conglomerados del Mioceno superior y dolomías y calizas triásicas alpujárrides. Las negociaciones que se llevaron a cabo para su construcción fueron complejas debido a la rivalidad que existe entre los municipios de Huércal Overa y Puerto Lumbreras. Con un caudal medio de $10 \mathrm{~L} / \mathrm{s}$, se trata del punto de agua más importante del término municipal, que se caracteriza por su clima árido. Actualmente es gestionada por la Comunidad de Regantes Aguas del Cabezo y sus aguas son utilizadas fundamentalmente para uso agrícola y ganadero. En 2018 se llevó a cabo una exploración de la galería que permitió disponer de un mapa detallado de la misma, se localizaron las lumbreras y entradas existentes, se realizó un estudio preliminar de la geología e hidrogeología del entorno y de la evolución de la calidad química del agua y del caudal en la galería. El agua subterránea presenta hipotermalismo y es incrustante, con un elevado contenido en sulfato y bajo en cloruro. Con esta información se realizó un balance hidráulico para el acuífero del Cabezo de la Jara, del que no existen estudios previos publicados. El acuífero presenta una superficie de afloramientos de $7 \mathrm{~km}^{2}$ y una compleja estructura geológica. Se deduce que el Coeficiente de Infiltración se encuentra entre 0,15 y 0,2 y los recursos medios anuales son del orden de 0,4 hmªño.

Palabras clave: balance de cloruros, carbonatos alpujárrides, conflictos por el agua, hipotermalismo, mina de agua.

\section{The nineteenth-century drainage gallery of Cabezo de la Jara. Constructive and hydrogeological characteristics (Huércal Overa, Almería)}

\begin{abstract}
A drainage gallery was built in the Cabezo de la Jara (Huércal Overa, Almería) aquifer between 1864 and 1886 for water catchment. Originally, it was about $2 \mathrm{~km}$ long through Miocene conglomerates and Triassic carbonates. Its construction process was complicated, due to the rivalry with the neighbouring municipality of Puerto Lumbreras (Murcia). With about $10 \mathrm{~L} / \mathrm{s}$ of average flow rate, it is supposed to be the most important water point of this predominantly arid region. Nowadays, the Irrigation Community of "Aguas del Cabezo" is in charge of the management of the gallery and it is mainly used to water the fields in the vicinity and provide water for the animals on the farms. The gallery was explored anew in 2018 and a detailed topography map has been produced including the location of all the luminaries, a geological study of the surroundings, a chemical analysis of the groundwater evolution and measurements of the flow. The results show thermal and encrusting phenomena of the groundwater, demonstrating high sulphate and low chloride parameters. Based on all the collected information the hydraulic resources of the Cabezo de la Jara aquifer have been evaluated and $7 \mathrm{~km}^{2}$ of outcrops and a complex geological structure where all the infiltrated water is discharge by the gallery have been calculated. The annual average resources are estimated at around $0.4 \mathrm{hm}^{3}$ with an infiltration coefficient of between 0.15 and 0.2 .
\end{abstract}

Keywords: alpujárride carbonates, chloride balance, drainage gallery, thermal water, water disputes. 


\section{Introducción}

El Cabezo de la Jara, de 1247 m de altitud, incluye parte de los municipios de Huércal Overa, Vélez Rubio (Almería), Puerto Lumbreras y Lorca (Murcia) (Fig. 1) y constituye un "islote de humedad y vegetación" (Gil Meseguer et al. 2009) en una zona predominantemente seca donde las precipitaciones medias anuales apenas alcanzan los $300 \mathrm{~mm}$ y la temperatura media es de $17^{\circ} \mathrm{C}$ con un clima de tipo mediterráneo semiárido. No existen cauces fluviales con caudal permanente en el término municipal, con excepción del Río Almanzora, cuyo funcionamiento hídrico es el de una rambla, con caudal episódico y violento, típica del sur de España. Ante esta situación, hasta la llegada de aguas procedentes del trasvase Tajo-Segura y, posteriormente del embalse del Negratín, la vida en esta zona ha sido posible gracias a la captación de recursos hídricos subterráneos, tanto para la agricultura como para el abastecimiento a la población y a la ganadería.

Según Gil Menseguer y Gómez Espín (2016) en el municipio de Huércal Overa hay más de 50 fuentes y manantiales, la mayoría alumbrados mediante la captación de técnicas de pozo horizontal (galerías). Estos

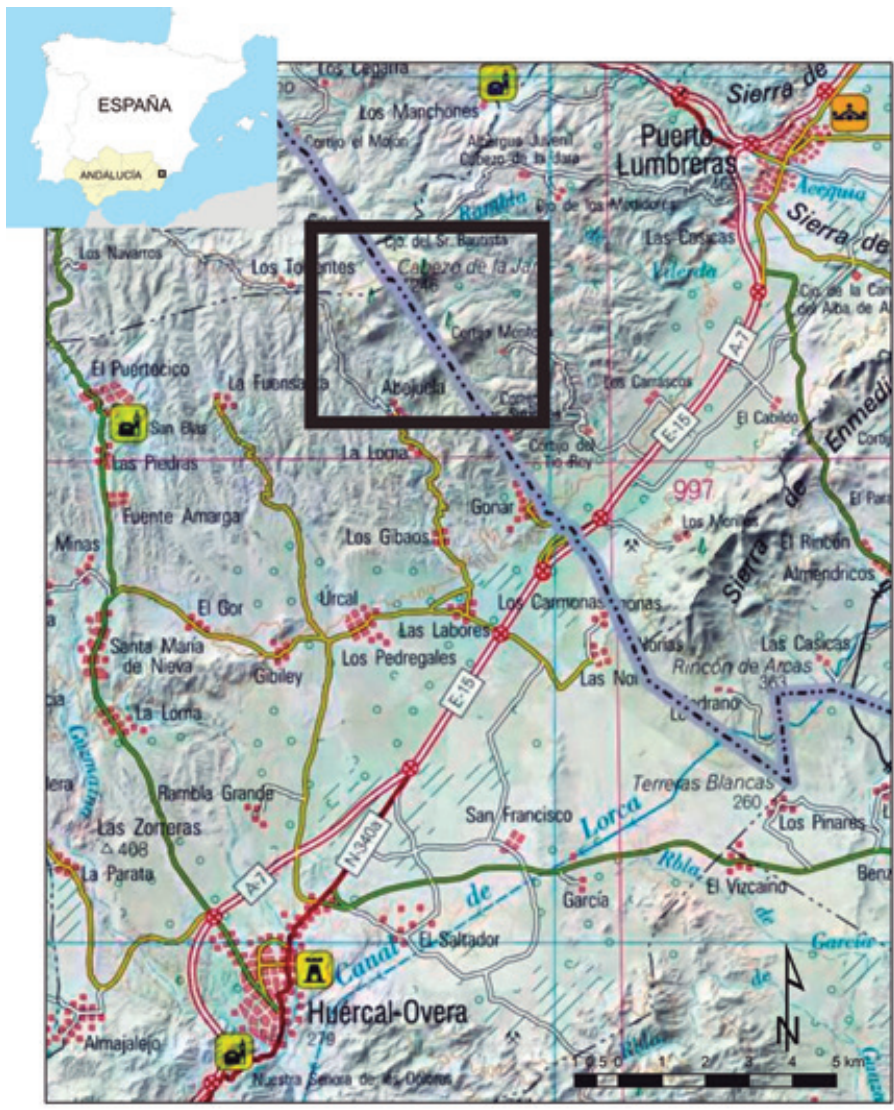

Figura 1. Contexto geográfico del Cabezo de la Jara.

Figure 1. Geological context of the Cabezo de la Jara autores indican que, por lo general, las captaciones responden al modelo de sangrado de aguas, de forma permanente o no, en las terrazas aluviales del Almanzora y a la construcción de galerías (minas de agua, qanat, cimbras, socavones..). Los caudales aportados por cada una de esas captaciones apenas suelen alcanzar el litro por segundo.

La galería del Cabezo de la Jara es el alumbramiento de agua más importante del término municipal de Huércal Overa, con un caudal medio anual de $10 \mathrm{l} / \mathrm{s}$. Está actualmente gestionada por los regantes de la Comunidad de Aguas del Cabezo, si bien, desde su construcción las aguas eran propiedad de la Sociedad de Aguas "Nuestra Señora de la Asunción", formada por un conjunto de accionistas, y la distribución de aguas se hacía mediante subasta al mejor postor (Gil Menseguer y Gómez Espín, 2016).

El agua alumbrada por la galería es conducida desde la bocamina hacia una balsa de la que parten tres ramales que la distribuyen por turnos entre los miembros de la comunidad de regantes. Estas acequias recorren la diputación de la Abejuela hasta alcanzar el núcleo urbano de Huércal Overa. En su día, el agua también fue utilizada para la producción de energía eléctrica, uso industrial en molinos e incluso para abastecimiento urbano (Gil Menseguer y Gómez Espín, op.cit.).

El objetivo de este artículo es describir los trabajos que se llevaron a cabo para la construcción de la galería y los conflictos generados tras el alumbramiento del agua, analizar su trazado y sus características constructivas y, por último, realizar un estudio preliminar de la geología e hidrogeología del entorno, del acuífero con el que se relaciona.

Antecedentes sobre la construcción de la galería

Se dispone de información sobre la construcción de la galería gracias a la obra Historia de la Villa de Huércal Overa y su comarca, escrita por Enrique García Asensio y cuya publicación original data de 1910. En este libro se describen detalladamente los avatares que dieron lugar a la excavación de la galería, de gran valor para poder interpretar algunos de los rasgos que se observan en su construcción.

Según García Asensio, la investigación de la presencia de agua en el Cabezo de la Jara se decide, porque: ...en la cima del Cabezo de la Jara, se observa abertura y un pozo de ruido, lo que ha dado ocasión al exponente a ocuparse en trabajar, por si puede ser agua lo que produzca este sonido... Una posibilidad es que la zona de la cima a la que se refiere sea lo que actualmente se denomina "el Zurrío del Agua", localizada en el afloramiento de carbonatos más elevado del Cabezo de la Jara, algo más de $2 \mathrm{~km}$ al norte de donde se construyó la galería. Esto indica que previamente no existía una surgencia natural de agua permanen- 
te en la zona, cuestión que se discute posteriormente. Este tipo de ruidos en las grietas de las montañas suele ocurrir cuando hay diferentes aberturas al exterior comunicadas entre sí. En ocasiones propicias, el movimiento del aire por el interior de estas grietas puede generar sonidos que se asemejan a la circulación del agua. La cota a la que se localiza el "Zurrío del Agua" y las características geométricas del acuífero hacen imposible que pueda existir circulación del agua próxima a la superficie en esta zona.

A pesar de lo anterior, parece que fueron estos sonidos los que sirvieron de acicate para la búsqueda de la valiosa agua, vital para regar estas tierras siempre sedientas donde las precipitaciones, como ya se ha indicado, son escasas. En febrero de 1821 se solicitaron permisos en el ayuntamiento de Huércal Overa para el alumbramiento de aguas en el Cabezo de la Jara y en ese mismo mes se iniciaron los trabajos; si bien, éstos fueron abandonados al poco de ser iniciados, posiblemente por la existencia de conflictos con los vecinos de Puerto Lumbreras (Murcia). La solicitud de permiso para la abertura de la galería, que finalmente llevó a su construcción, se hizo el 15 de mayo de 1864 y las obras debieron comenzar inmediatamente, pues el 16 de julio de 1866 se dice que salía por la boca de la mina nada menos que un caudal de $0,5 \mathrm{~m}^{3}$ (es de suponer que "por segundo"). Esto es verosímil, pues la galería debió cortar el nivel freático algunos metros por debajo de la cota a la que se situaba de forma natural, con la consiguiente desaturación del acuífero hasta establecerse un nuevo nivel a la cota de la galería. El caudal es elevado durante el tiempo en que esto se produce y va paulatinamente disminuyendo para, finalmente, quedar en el caudal de descarga natural que el acuífero puede drenar en función de sus recursos medios. Esta es la explicación más probable a lo ocurrido, ya que, posteriormente, se indica que el caudal de descarga se establece en $27 \mathrm{l} / \mathrm{s}$, y se aporta
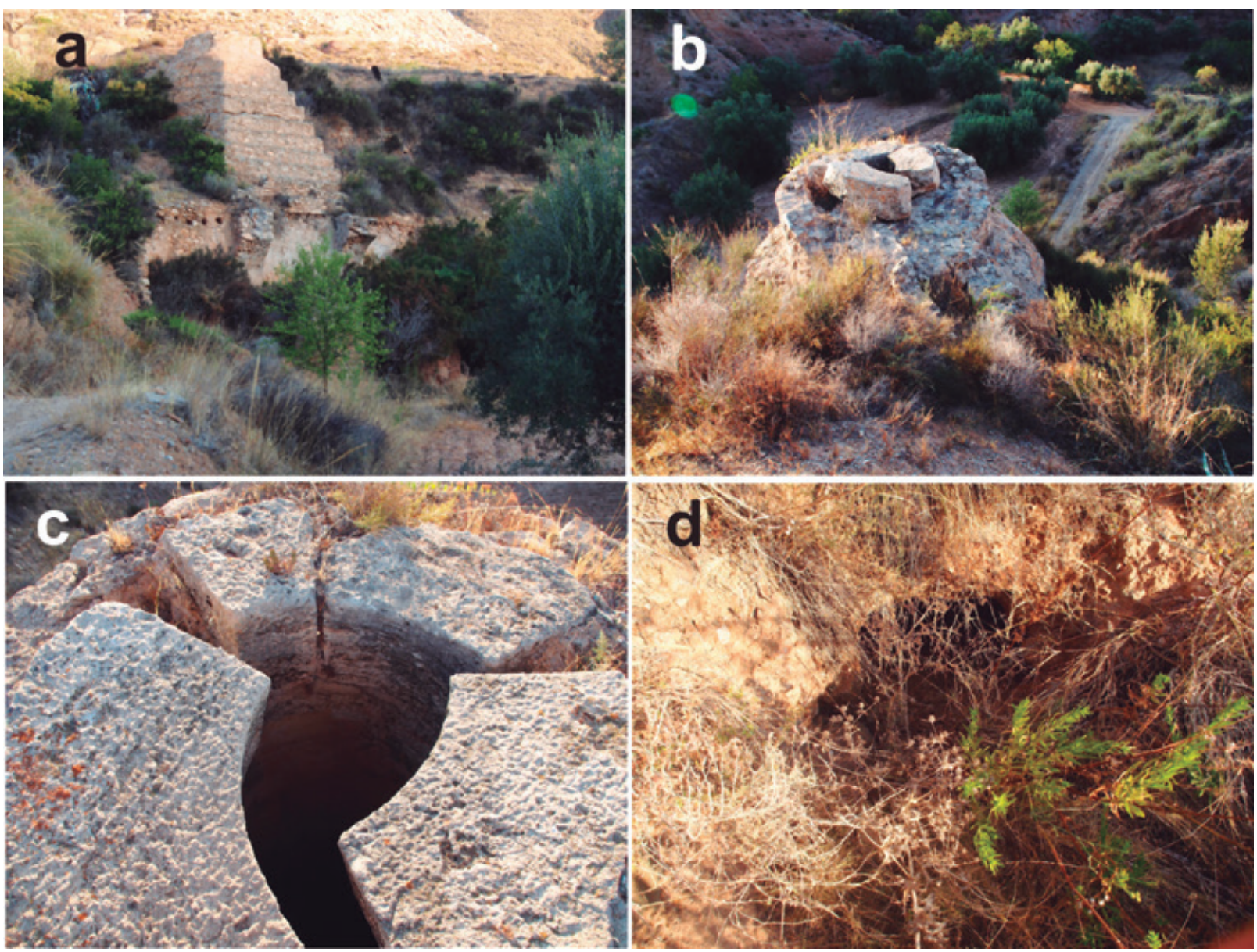

Figura 2. a) Antiguo molino de cubo abandonado; b) boca de entrada de agua hacia el molino; c) detalle de la boca de entrada de agua; d) salida de la galería que alimentaba la acequia del molino.

Figure 2. a) Old abandoned bucket mill; b) point of water entrance to the mill; c) detail of the point of water entrance; d) old exit of the gallery to feed the channel to the mill. 
además otro dato importante y es que el agua presenta hipotermalismo, lo que indica una circulación profunda y compleja por el acuífero.

Este tipo de obras, lógicamente, se inician con la construcción de lumbreras. El documento indica que el agua apareció en la novena lumbrera a una profundidad de $67 \mathrm{~m}$. Por la profundidad, tal vez podría corresponder con la denominada en la figura 3 como lumbrera 9 , de las 10 que pudieron topografiarse por la Asociación Espeleológica Velezana (AEV) en 2018. De todas formas, este dato es confuso, pues según se indica posteriormente la galería se reconstruyó a mayor profundidad debido a los problemas surgidos con los regantes murcianos.

A raíz del alumbramiento de las aguas en el término de Huércal Overa, desde el término de Puerto Lumbreras se llevó a cabo la construcción de otra galería a menor cota en una zona cercana, que provocó la desecación de la primera. El problema se resolvió con la nueva construcción, realizada aproximadamente en 1886, de otra más profunda en Huércal Overa. Esto podría explicar la existencia de un antiguo molino abandonado por encima de la galería (Fig. 2), alimentado por una galería distinta, cuya boca se localiza a cota $734 \mathrm{~m}$ s.n.m. (Fig. 2d). La salida actual de la galería se encuentra a la cota $716 \mathrm{~m}$ (Figs. 3 y 4). Por otra parte, en la Entrada 3 (Figs. 3 y 4 ) se encuentra otra galería superior que conecta con la lumbrera 4 y continúa en la pared contraria (Fig. 6b). Esta galería no se ha investigado y tal vez esté relacionada con la que alimentaba el molino, pues se encuentra a una cota similar. De hecho, García Asensio (1910) habla también de la construcción de un molino poco después de haberse alumbrado el primer caudal.

En 1887, tras la construcción de la nueva galería a menor cota, se cita otra vez la descarga de un caudal de 27 l/s. Por último, García Asensio (op. ct.) menciona que en 1910 se hicieron otras labores, que debieron ser de reparación en algunas partes de la galería, con lo que se logró incrementar el caudal en unos $10 \mathrm{l} / \mathrm{s}$ que seguramente se habrían perdido por deterioros previos en su trazado.

En 1995, la entonces denominada Sociedad de Aguas La Asunción, envió un escrito a la Delegación Provincial de la Consejería de Industria, Comercio y Turismo de Almería en la que manifiestan su preocupación sobre posibles desperfectos que la explotación de la Cantera Gaona, situada en sus cercanías, pudiese estar provocando en la galería. El propietario de la Cantera remitió a la Delegación un informe realizado por el Ingeniero de Minas Miguel $\mathrm{M}^{\mathrm{a}}$ Martínez Díez, donde se concluyó que estos desperfectos no habían podido producirse. En este informe se incluyó el único mapa previo existente sobre la galería, si bien, realizado sobre la base de la ubicación superficial de algunas de las lumbreras. Como consecuencia del desacuerdo, la Delegación solicitó al IGME su opinión. Este organismo emitió una nota técnica en febrero de 1996, donde igualmente se concluyó que la galería no se encuentra afectada por la explotación de la cantera (IGME, 1996).

\section{Materiales y Métodos}

\section{Topografía de la galería}

La topografía de la galería fue realizada por la Asociación Espeleológica Velezana (AEV) en varias jornadas de campo entre los meses de agosto y septiembre de 2018, con la utilización de un medidor laser Disto X310 de Leica (Fig. 6a) en el que se sustituyó la placa base proporcionada por el fabricante por otra diseñada por Beet Heab (http://paperless.bheeb.ch/), que tras su correcta calibración permite medir en un solo disparo la distancia entre puntos, su inclinación y su ángulo con respecto al norte magnético. Es necesario, además, sustituir el sistema de pilas convencionales con una batería no magnética. La placa también permite transferir los datos al mismo tiempo de su toma, mediante bluetooth, a un dispositivo que puede ser un móvil, una tablet o un ordenador para su posterior procesamiento. En este caso se utilizó un teléfono móvil Blackview con un IP-68 que permite trabajar en presencia de barro y humedad. El medidor Disto también está preparado para trabajar en esas condiciones con un IP-65. Los datos son procesados con la aplicación para Android Topodroid diseñado por Corvi (https:// sites.google.com/site/speleoapps/home/topodroid). Con la calibración realizada se consigue una precisión con un error en el ángulo del orden de $0,2^{\circ}$.

\section{Hidroquímica e hidrometría}

El 22 de septiembre de 2018 se tomaron tres muestras de agua, la primera en la salida de la bocamina de la entrada 1, la segunda en el interior de la galería a la altura de la lumbrera 4, que corresponde más o menos con la mitad de recorrido que el agua tiene desde su nacimiento hasta la salida por la galería, y la tercera directamente en su nacimiento en una fractura en los carbonatos triásicos (Fig. 3). En los tres casos se tomaron en campo medidas de conductividad eléctrica del agua (CE) y de la temperatura. Se dispone además de otros 2 análisis químicos realizados en dos muestras tomadas en junio de 2016 por la Comunidad de Regantes Aguas del Cabezo y analizadas en el laboratorio CAASA (Lorqui, Murcia). Las otras tres muestras tomadas en el marco de este trabajo fueron analizadas en el laboratorio de Tres Cantos (Madrid) del IGME. 


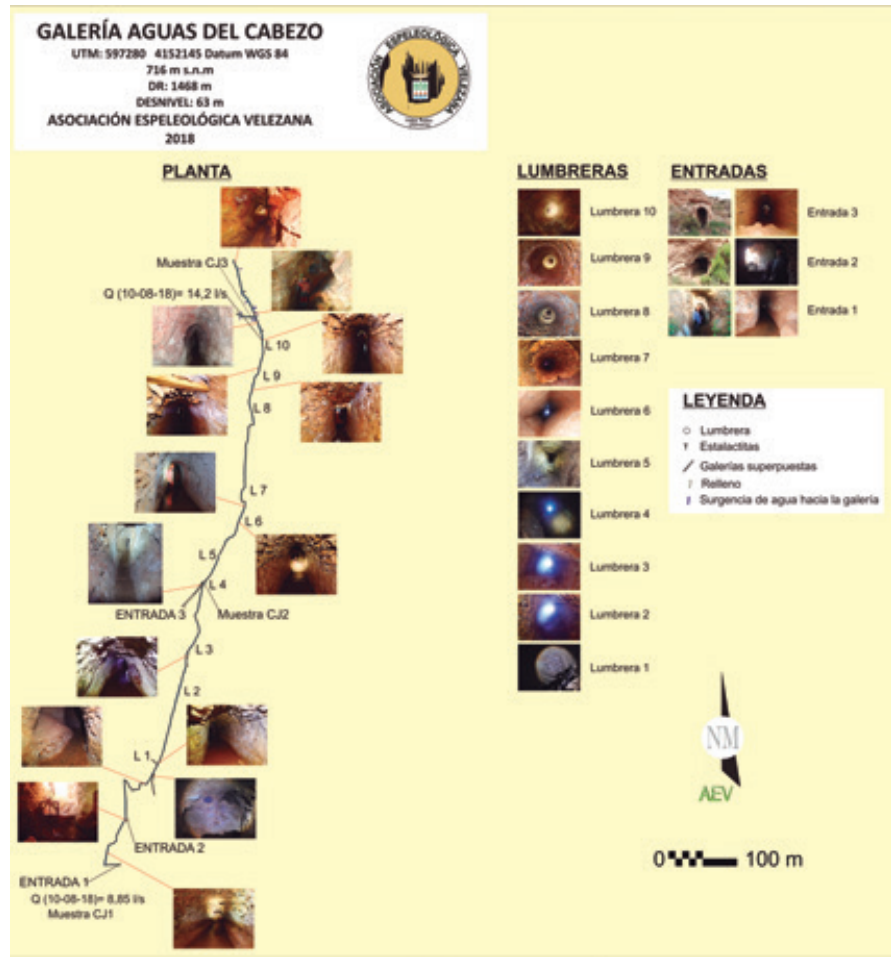

Figura 3. Planta de la zona de galería topografiada con inclusión de fotografías de zonas significativas. Se adjuntan también en el mapa los puntos de muestreo y los que se realizaron aforos y el resultado obtenido. Las coordenadas dadas en el cajetín ser refieren al punto denominado como ENTRADA 1.

Figure 3. Map of the topographic gallery with inclusion of photographs in significant zones. Sampled point and flow measurement points and the results are included too. The coordinates in the box correspond to ENTRANCE 1.

El 10 de agosto de 2018 se hizo un aforo en la salida del agua de la bocamina de la entrada 1 y otro más en el interior de la galería, inmediatamente aguas abajo de la zona donde la galería corta los carbonatos triásicos. Se dispone además de 12 aforos realizados por la comunidad de regantes entre mayo de 2015 y abril de 2018 aproximadamente cada tres meses. Estos aforos se realizaron instalando un contador en la acequia y haciendo pasar todo el caudal por su sección.

\section{Resultados}

\section{Topografía de la galería}

En la figura 3 se muestra la planta de la galería en la que se han incorporado algunas fotos que muestran secciones significativas. También se han incluido fotos de todas las lumbreras y de las tres entradas localizadas. Solo se topografió la parte activa de la galería, si bien la inactiva también fue explorada.

La longitud topografiada incluyendo el trazado de las lumbreras y las galerías laterales fue de $1468 \mathrm{~m}$, con un desnivel total de $63 \mathrm{~m}$ entre la boca de la lumbrera más elevada y la Entrada 1. Por otra parte, el desnivel medido entre la Entrada 1 y el final de la galería fue de tan solo $1 \mathrm{~m}$ (0,68 por mil), sin que el método de topografía permita una mayor precisión (Fig. 4). La Entrada 1 es una galería de 20 m perpendicular a la principal. En el punto en que conectan existe un partidor que impide que el agua circule por la galería primigenia. A unos $70 \mathrm{~m}$ desde el partidor se localiza la Entrada 2, bajo el talud del camino hacia el molino, que servía para surtir de agua a las huertas de esa zona. Por último, de la base de la lumbrera 4 parte una galería ascendente que conecta con otra galería superior, ya mencionada, desde donde se alcanza la Entrada 3 (Fig. 3).

Se han localizado un total de 16 lumbreras, 10 de ellas en la zona topografiada, 5 en la traza de la galería no topografiada que discurre hacia el S y una más, la lumbrera 11, que se encuentra fuera de traza más al norte del final del ramal principal topografiado. En la figura 3 se muestran las fotografías desde el interior

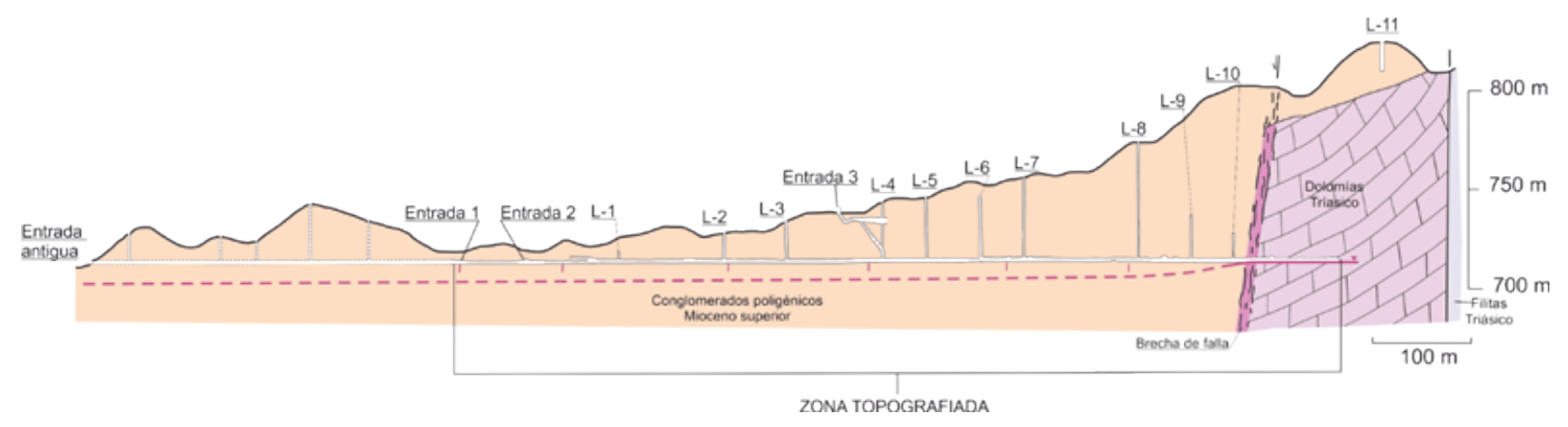

Figura 4. Perfil geológico-hidrogeológico de la galería, de dirección N16E, con indicación de la zona topografiada. En morado con línea continua se muestra la posición del nivel piezométrico y con línea discontinua su posición supuesta.

Figure 4. Geological-hydrogeological cross section of the gallery in N16E direction. Topographic zone is indicated. Continuous purple line shows the position of the water table and dashed line its possible position. 


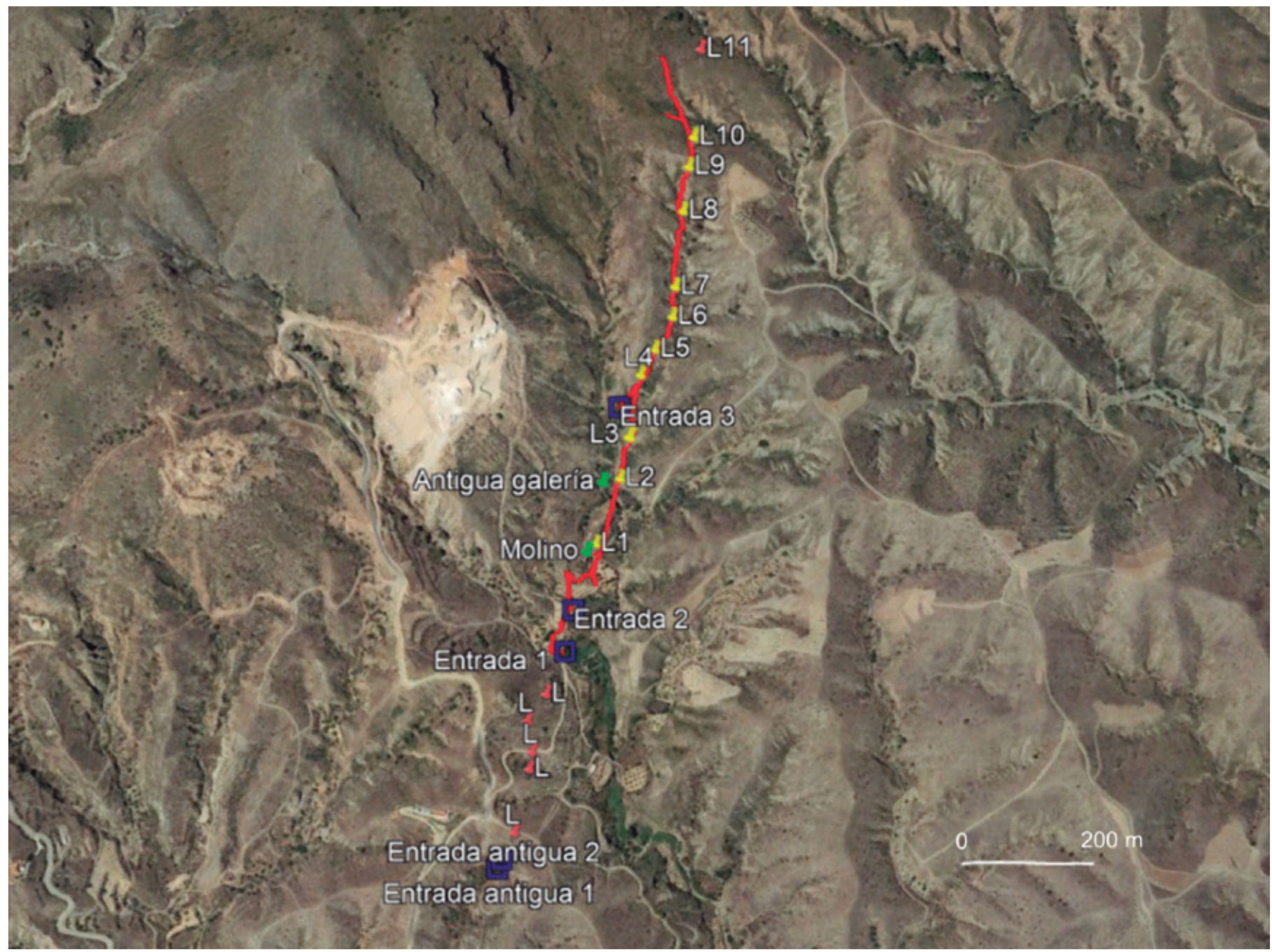

Figura 5. Proyección de la zona topografiada y situación de entradas y lumbreras en la ortofoto (imagen tomada de Google Earth 6-122016).

Figure 5. Projection of the topographic area and location of the entrances and luminaries.

de la galería de las 10 que se encuentran en la zona topografiada.

La galería discurre en dirección SSO-NNE (Figs. 3 y 5) excavada en su mayor parte en conglomerados, arenas y limos parcialmente cementados de edad Mioceno superior. Estos materiales se superponen de forma discordante a calizas y dolomías delTriásico que son las que componen el acuífero principal (Fig. 4). EI cambio litológico se encuentra a unos $850 \mathrm{~m}$ desde la boca de la Entrada 1 y se produce primero a través de una franja de unos $15 \mathrm{~m}$ de espesor completamente brechificada (Figs. 4 y 9 a y b), para después cortar la formación carbonatada triásica (Fig. 9c). Inmediatamente, la galería se bifurca con un ramal en dirección
O, que alcanza unos $30 \mathrm{~m}$ de desarrollo horizontal. EI ramal principal continúa en dirección NNO durante unos $85 \mathrm{~m}$ más.

En los primeros metros del ramal secundario es donde se encuentran los mayores aportes de agua, a favor de líneas de fractura y de superficies de estratificación. También se localizan aportes en el canal principal, especialmente en sus primeros metros cercanos a la bifurcación. La estratificación se midió en dos puntos y sigue aproximadamente la dirección de la galería principal, N155E con buzamiento de $52^{\circ}$ hacia el O y N167E $49^{\circ}$ al O (Figs. 9c y d). La galería secundaria finaliza en una pared de roca y la principal en una pared empedrada (Fig. 9d). 


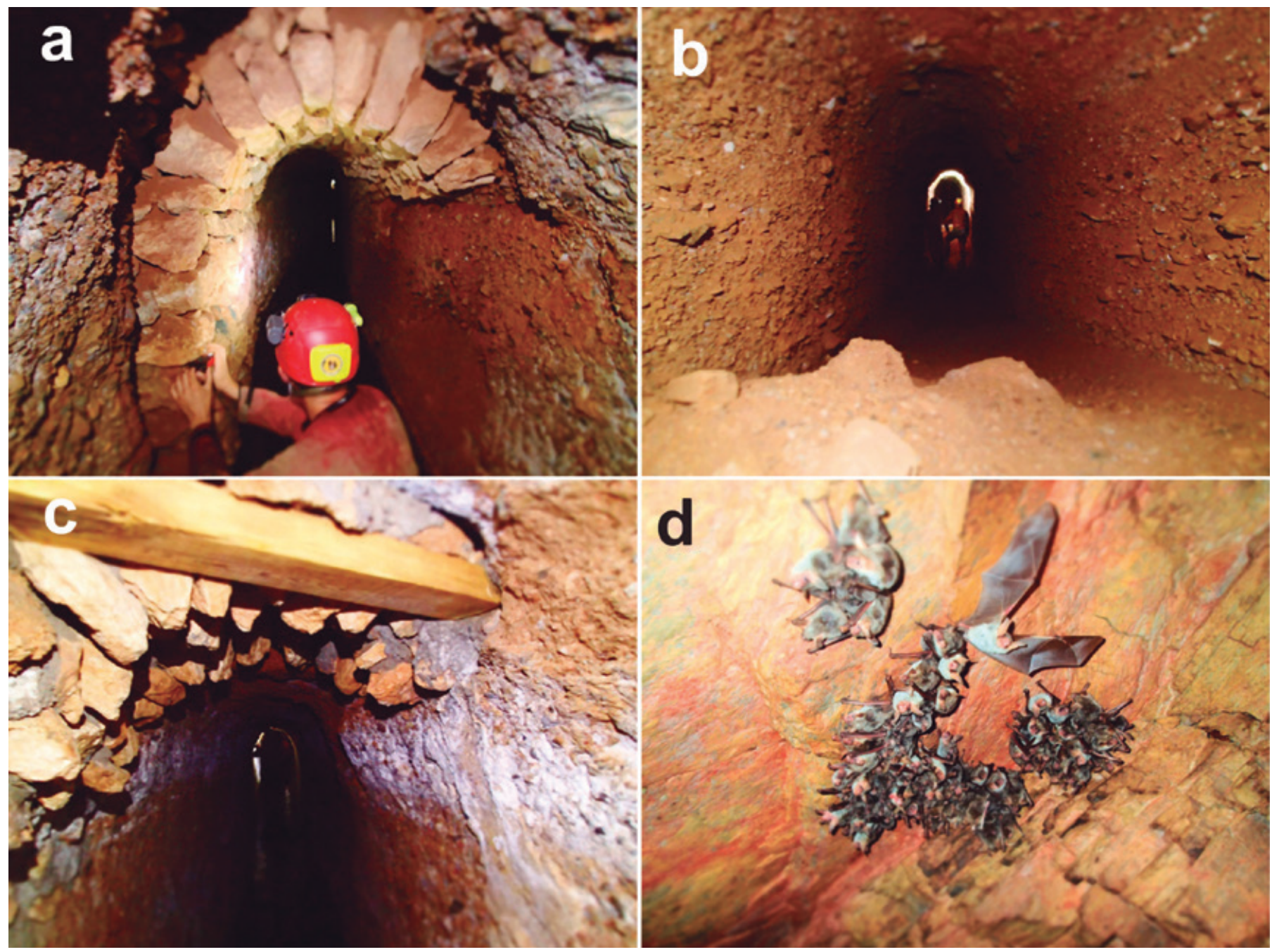

Figura 6. a) Labores de topografía en una zona de galería parcialmente empedrada; b) galería horizontal superior que conecta la Entrada 3 con la lumbrera 4 ; c) Refuerzo con una viga de madera en el techo de la galería; d) colonia de murciélagos en la zona más profunda de la galería.

Figure 6. a) Topography work in an area with partially paved roof; b) upper horizontal gallery from entrance 3 to luminary 4; c) reinforcement with a wooden beam in the ceiling of the gallery; d) bat colony in the deepest part of the gallery.

La galería presenta anchuras en torno a $1 \mathrm{~m}$, a veces menor, con paredes regulares que en buena parte de su trazado están revestidas por mampostería (Figs. 6ay $7 \mathrm{a}, \mathrm{b}$ y c). La altura es del orden de $1 \mathrm{~m}$ en los primeros tramos, para pasar a tener unos $2 \mathrm{~m}$ a partir de la lumbrera 4. Los techos también aparecen embovedados de piedra en muchos sitios, y en algunos reforzados con vigas de madera (Fig. 6c). En general se encuentra en buen estado, si bien hay rellenos de tierra bajo todas las lumbreras, que producen un efecto de embalsamiento del agua. En la lumbrera 6 , justo al inicio de una zona revestida se encuentra una roca desprendida que provoca el embalsamiento más importante, pero que no impide la circulación del agua (Fig. 7a).
Las paredes y techos en la zona donde la galería penetra en los carbonatos son más irregulares, con el aspecto en algunas zonas de una cueva natural. Las discontinuidades se aprecian bien, entre las que destacan las superficies de estratificación, fuertemente inclinadas hacia el $\mathrm{O}$.

Por otra parte, la galería es el refugio de una importante colonia de murciélagos de la especie Myotis Myotis (murciélago ratonero grande) (Fig. 6d). Las mayores concentraciones se han observado en la zona final de roca y también en algunas lumbreras. En la zona final se observa en algunas partes abundante guano. 

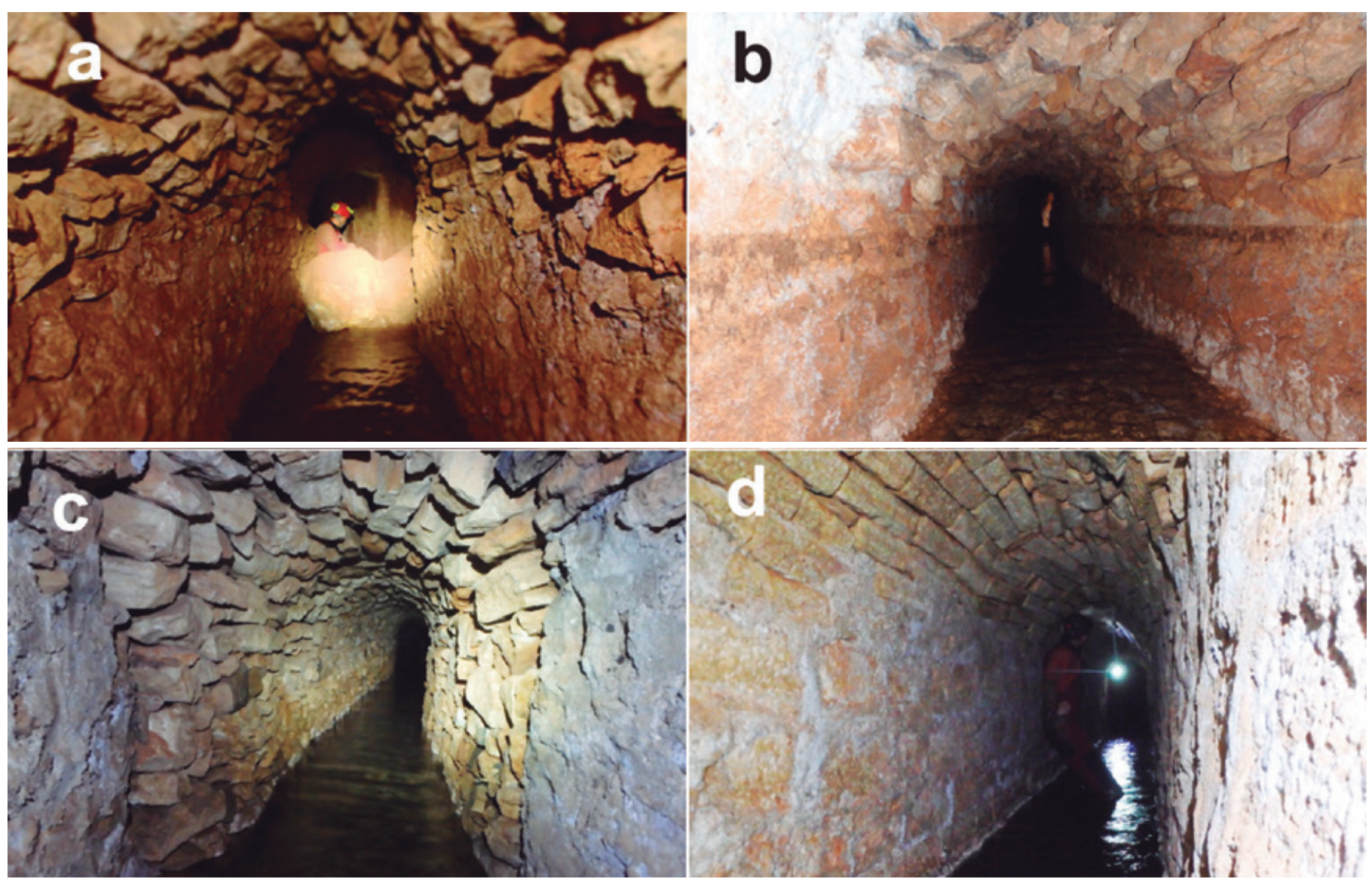

Figura 7. a) Derrumbe localizado bajo la lumbrera 6 que provoca un embalsamiento del agua en la galería; b), c), y d) distintos tipos de revestimientos de piedra.

Figure 7. a) Collapse under luminary 6 that causes an accumulation of water in the gallery; b), c) and d) different kinds of stone paving on the ceilings.

\section{Hidroquímica e hidrometría}

Además de las muestras de agua tomadas en septiembre de 2018, se dispone de dos más recolectadas por la Comunidad de Regantes en junio de 2016 y analizadas en un laboratorio distinto (Tabla 1). Todas las muestras presentan una facies sulfatada cálcico magnésica (Fig. 14) con valores del sulfato en torno a $1000 \mathrm{mg} / \mathrm{l}$ y de Ca generalmente por encima de 300 $\mathrm{mg} / \mathrm{l}$. La temperatura del agua fue de $23,4^{\circ} \mathrm{C}$ en la muestra CJ 3 y de $22,2^{\circ} \mathrm{C}$ en la CJ 1 y la Conductividad Eléctrica (CE) estuvo comprendida entre 1937 y 1961 $\mu \mathrm{S} / \mathrm{cm}$ con los valores más elevados en muestra tomada a la salida de la bocamina (CJ1) aunque con un valor casi idéntico al de la muestra CJ2.

\begin{tabular}{|c|c|c|r|r|r|r|r|r|r|r|r|r|r|l|}
\hline Muestra & Fecha & Tem & $\begin{array}{c}\mathrm{CE} \\
\text { campo }\end{array}$ & $\mathrm{HCO} 3$ & \multicolumn{1}{c|}{$\mathrm{Cl}$} & \multicolumn{1}{c|}{$\mathrm{SO} 4$} & $\mathrm{NO}$ & $\mathrm{Ca}$ & $\mathrm{Mg}$ & $\mathrm{Na}$ & $\mathrm{K}$ & $\mathrm{SiO} 2$ & Lab & Observaciones \\
\hline $\mathrm{M} 1 \mathrm{~B}$ & $20 / 06 / 2016$ & & & 307 & 25 & 975.19 & 0.74 & 311 & 98 & 18.33 & 2 & 17 & CAASA & Muestratomada en interior de la mina \\
\hline $\mathrm{M} 2 \mathrm{~B}$ & $20 / 06 / 2016$ & & & 212 & 26 & 980.35 & 0 & 277 & 99 & 18.42 & 2 & 17 & CAASA & Muestra tomada en la acequia \\
\hline $\mathrm{Cl} 1$ & $22 / 09 / 2018$ & 22.2 & 1961 & 290 & 19 & 1050 & 0 & 324 & 124 & 23 & 2 & 18 & IGME & $\begin{array}{l}\text { Muestra tomada en la salida de la } \\
\text { bocamina }\end{array}$ \\
\hline $\mathrm{Cl} 2$ & $22 / 09 / 2018$ & 22.9 & 1956 & 294 & 20 & 1060 & 0 & 326 & 124 & 23 & 2 & 18 & IGME $\begin{array}{l}\text { Muestra tomada en el interior a la } \\
\text { altura de la lumbrera 4 }\end{array}$ \\
\hline $\mathrm{Cl} 3$ & $22 / 09 / 2018$ & 23.4 & 1937 & 292 & 19 & 1030 & 0 & 332 & 118 & 23 & 2 & 18 & $\begin{array}{l}\text { Muestra tomada en el interior en } \\
\text { la surgencia en una fractura de los } \\
\text { carbonatos }\end{array}$ \\
\hline
\end{tabular}

Tabla 1. Resultados de los análisis químicos realizados en el agua drenada por la galería de la C.R. Aguas del Cabezo. Valores en mg/l excepto Temp. en ${ }^{\circ} \mathrm{C}$ y $\mathrm{CE}$ en $\mu \mathrm{S} / \mathrm{cm}$.

Table 1. Results of the chemical analysis of the water sampled in the gallery. Values in $\mathrm{mg} / \mathrm{l}$ except Temp. in ${ }^{\circ} \mathrm{C}$ and $\mathrm{EC}$ in $\mu \mathrm{S} / \mathrm{cm}$. 


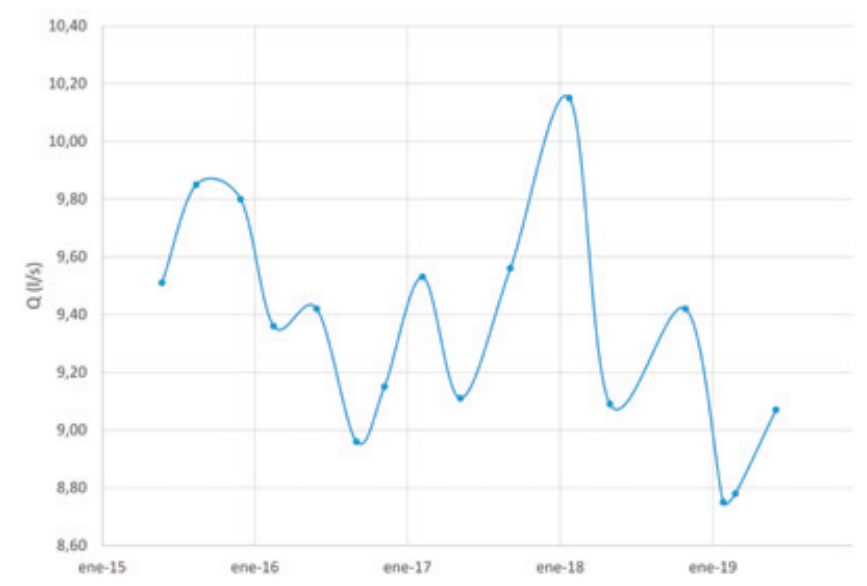

Figura 8. Evolución de caudales en el canal de salida de la galería Aguas del Cabezo. Medidas tomadas por la Comunidad de Regantes.

Figure 8. Evolution of the discharge in the gallery. Measures taken by the Irrigation Community.
En la figura 8 se muestra un gráfico con la evolución de caudales a partir de aforos realizados por la Comunidad de Regantes. Con estos datos se puede asignar un caudal medio de $9,4 \mathrm{l} / \mathrm{s}$ para el periodo comprendido entre mayo de 2015 y junio de 2019 con los máximos normalmente situados en el invierno y los mínimos en el verano-otoño, si bien, no hay datos suficientes para precisar esto. El 10 de agosto de 2018 se realizó un aforo en el mismo sitio y se obtuvo un caudal de $8,85 \mathrm{l} / \mathrm{s}$, que está en el mismo rango de los aportados por la Comunidad de Regantes.

También se realizó un aforo en el interior de la galería en una zona rectilínea justo aguas abajo de la zona de contacto entre los conglomerados miocenos y los carbonatos triásicos (Fig. 3), el caudal obtenido fue de $14,2 \mathrm{l} / \mathrm{s}$, notablemente superior al obtenido a la salida de la galería.

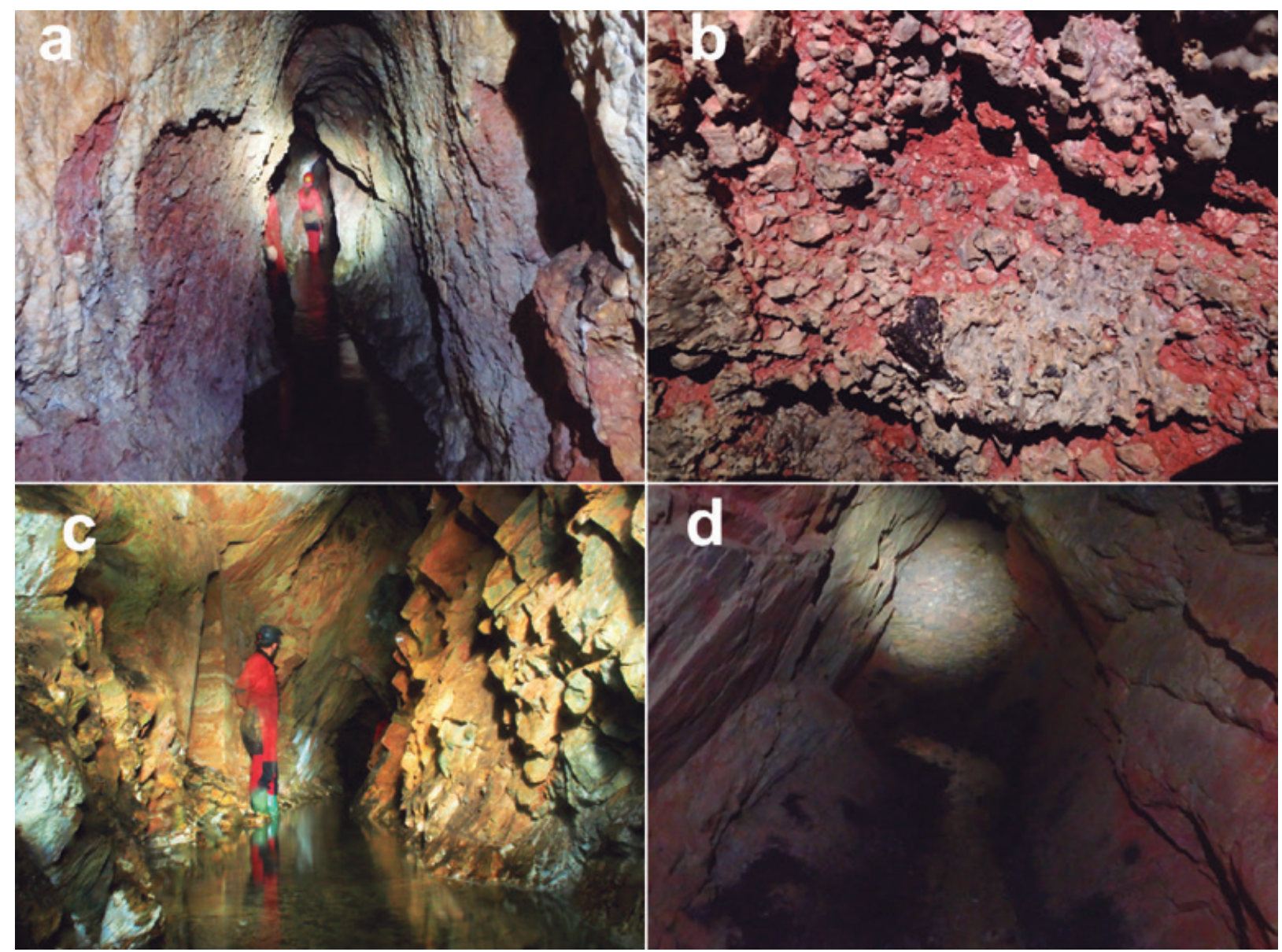

Figura 9. a) Zona brechificada en el contacto entre los conglomerados y los carbonatos; b) detalle de las brechas; c) Carbonatos triásicos en la zona donde la galería se bifurca, se observan las superficies de estratificación fuertemente inclinadas a la izquierda; d) Pared empedrada que marca el final de la galería principal.

Figure 9. a) Brecciated zone in contact between conglomerated Miocene and Triassic carbonates; b) detail of the brecciated zone; c) Triassic carbonates in the area where the gallery forks with the stratification strongly leaning to the left; $d$ ) paved wall where the gallery ends. 


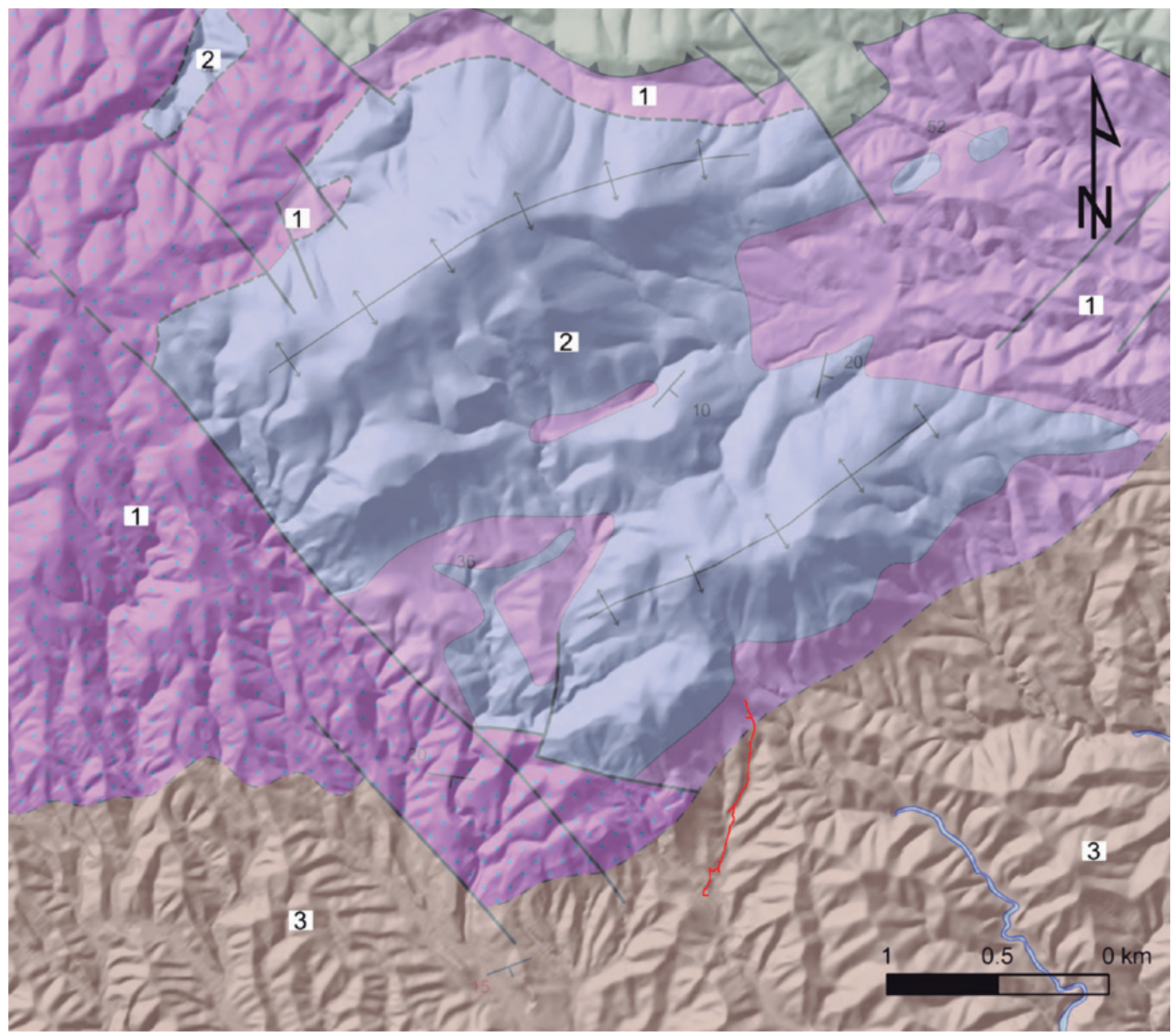

Figura 10. Mapa geológico del Acuífero del Cabezo de la Jara según el Mapa continuo digital de España (GEODE, IGME). 1: Filitas y cuarcitas, Tríasico inferior; 2: Calizas y dolomías, Triásico; 3: Conglomerados poligénicos, Mioceno superior. En línea roja la traza de la galería. MDT 5 m IGN.

Figure 10. Geological map of the Cabezo de la Jara Aquifer according to the digital continuous map of Spain (GEODE, IGME). 1: phillites and cuarcites, low Triassic; 2: limestones and dolomites, Triassic; 3: Poligenic conglomerates, upper Miocene. Gallery traced in red line.

\section{Discusión}

\section{El acuífero del Cabezo de la Jara}

Este acuífero se encuentra incluido en la Cuenca del Segura y no se conocen estudios específicos publicados sobre sus características hidrogeológicas (IGME, 2010). Sin embargo, existe un trabajo interno de la Confederación Hidrográfica del Segura en el que se evalúan los recursos existentes en base al caudal drenado por la galería (CHG, 1995). Por otra parte, la cartografía geológica de los afloramientos que lo constituyen data del año 1978 (Voermans et al., 1979) y necesita de una profunda revisión (Fig. 10). Tampoco existe información piezométrica ni datos hidroquímicos previos del agua subterránea.

El acuífero, constituido por un espesor máximo de $300 \mathrm{~m}$ fundamentalmente de dolomías, está formado por un afloramiento de carbonatos que da lugar a tres 


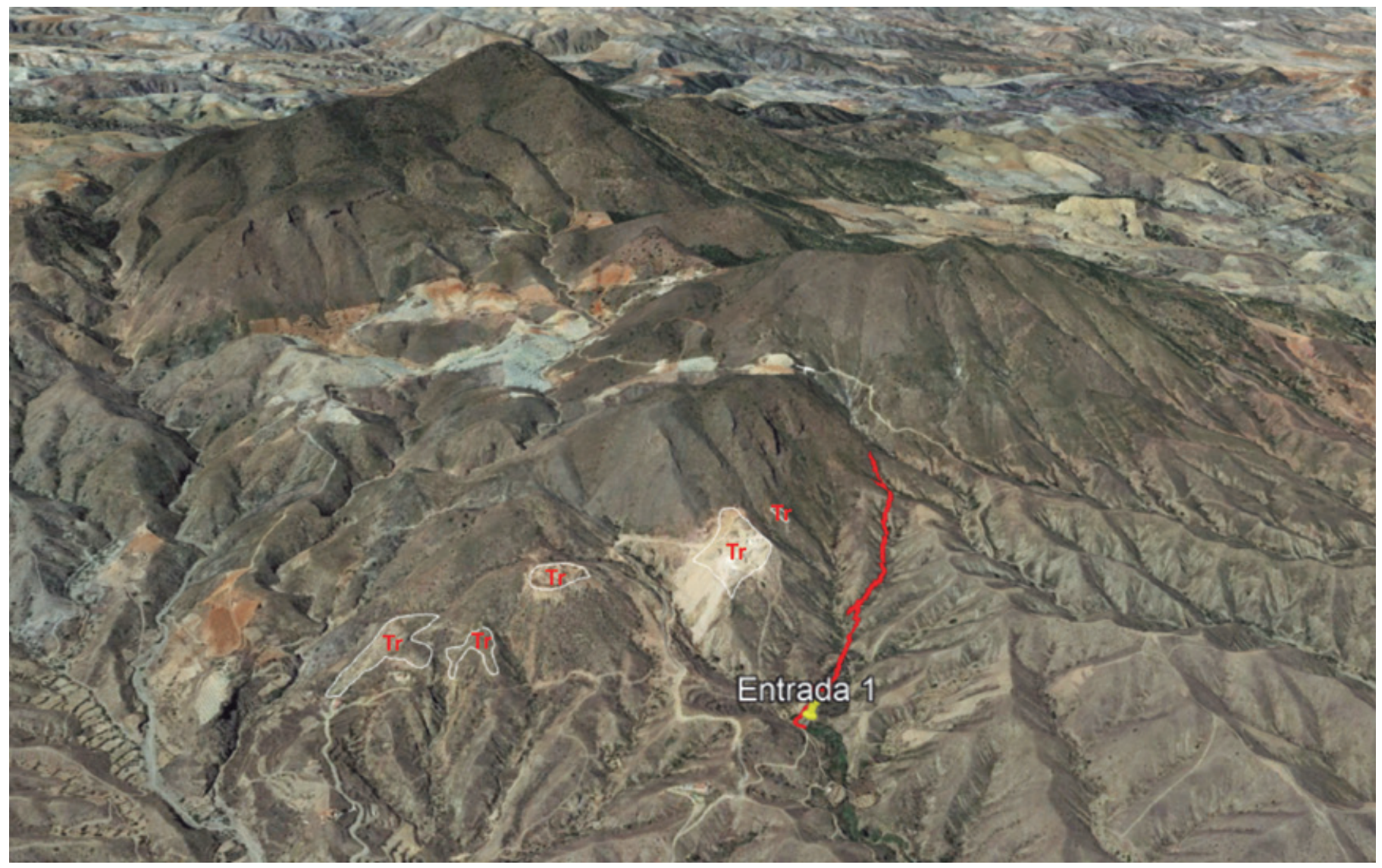

Figura 11. Imagen tridimensional del acuífero del Cabezo de la Jara y su relación con la Galería. Los relieves están formados por carbonatos triásicos, los materiales de tonos violáceos-azulados corresponden a filitas triásicas y el recubrimiento detrítico de tonos anaranjados que se observa en la parte inferior derecha, sobre el que discurre mayoritariamente la galería, son conglomerados poligénicos del Mioceno superior. Se incluye también la cartografía de las mesas de travertinos localizadas (Tr). (Imagen tomada de Google Earth 16/07/2018).

Figure 11. Three-dimensional image of the Cabezo de la Jara aquifer and its relationship with the gallery. The reliefs are composed by Triassic carbonates, the materials with purple-blues tones are Triassic phillites and detrital cover that is observed in the lower right-hand side correspond with polygenic conglomerates. The cartography of the travertine tables (Tr) is also included. (Image from Google Earth 07/16/2018).

relieves montañosos más o menos aislados entre sí (Fig. 11). Su estructura geológica es compleja y no bien conocida. En la zona donde se encuentra la galería aparecen al menos tres masas de travertinos adosadas al borde del relieve situado más al sur. Dos de ellas son explotadas por canteras como roca ornamental. EI relieve S se encuentra en su mayor parte separado del resto del acuífero por una banda de filitas que aflora al $\mathrm{Ny} \mathrm{NE}$, posiblemente debido a la presencia de una falla de componente direccional. Sin embargo, hacia el NO los carbonatos tienen continuidad cartográfica con los otros dos relieves por una estrecha banda.

Todos los límites del acuífero son impermeables, por la existencia de filitas, excepto el borde S y SE, justo donde se localiza la galería y los afloramientos de travertinos. En este sentido, la cartografía mostrada en la figura 10 no es correcta. En esta zona, los carbonatos aparecen recubiertos de forma discordante por la formación conglomerados del Mioceno supe- rior. Posiblemente esta es la causa por la que no existen manantiales importantes localizados en el límite meridional del acuífero, ya que el agua subterránea infiltrada en los carbonatos se descarga de forma lateral a través del acuífero mioceno, que tiene una menor permeabilidad.

Los tres relieves se encuentran conectados desde el punto de vista hidrogeológico, condición necesaria para explicar el caudal que surge por el manantial. La presencia de hipotermalismo indica que el agua ha circulado por zonas profundas antes de aflorar en la galería, lo que es indicio de una compleja estructura geológica. En la zona de surgencia en contacto con los carbonatos, el agua tiene una temperatura de $23,4^{\circ} \mathrm{C}$, unos $6^{\circ} \mathrm{C}$ superior a la temperatura media anual del aire en la zona; si bien solo rebasa en $1,4^{\circ} \mathrm{C}$ la condición para que se considere como termal.

Los travertinos muestran la posición de antiguos manantiales (paleo-manantiales) cuando el nivel freá- 

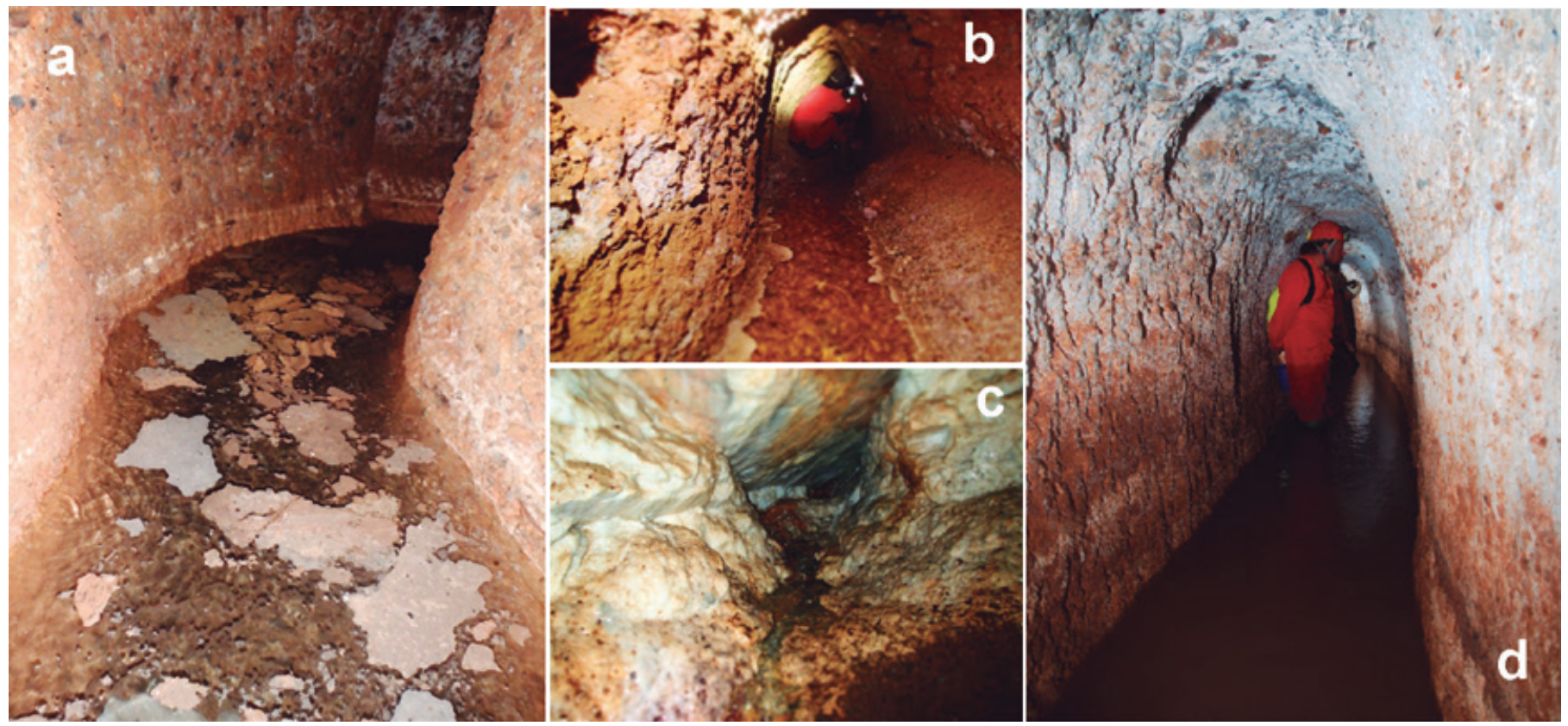

Figura 12. a) Precipitaciones de carbonato cálcico en forma de calcita flotante; b) precipitaciones de calcita en los bordes de la galería (aceras); c) fractura por donde mana agua con precipitaciones de calcita justo en el nacimiento; d) paredes recubiertas con precipitados blancos.

Figure 12. a) Precipitation of calcium carbonate in the form of floating calcite; b) precipitation of calcite on the edge of the gallery (shelf stones); c) fracture with precipitation of calcite where the water flows; d) white precipitates in the wall of the gallery.

tico se encontraba más elevado. No se sabe la época en la que estos manantiales funcionaban, pero sin duda es anterior a los periodos históricos. Su desaparición posiblemente fue ocasionada por el avance de la erosión por la incisión de los barrancos en los conglomerados miocenos, lo que provocó el descenso del nivel freático $y$, como consecuencia, la desecación de los manantiales que formaron los travertinos. Las aguas actualmente son incrustantes, como prueba la existencia de precipitaciones de carbonato cálcico, tanto en las mismas fracturas donde nace, como en la propia galería en forma de aceras y de calcita flotante (Fig. 12).

\section{Balance hidráulico}

Actualmente el nivel piezométrico está condicionado por la existencia de la galería, que provoca que el agua infiltrada en el acuífero se drene por ella. Como se ha indicado en las líneas anteriores a finales del siglo XIX y principios del siglo XX se cita un caudal de $27 \mathrm{l} / \mathrm{s}$. Los datos de aforos recientes indican que el caudal medio drenado por la galería podría situarse en torno a los $10 \mathrm{l} / \mathrm{s}$.

Con la información disponible es posible hacer una pequeña estimación del volumen de recarga media anual en el acuífero. La superficie de afloramientos es de $7 \mathrm{~km}^{2}$ y la precipitación media en la zona es de 300 $\mathrm{mm}$. El coeficiente de infiltración con precipitaciones de este orden en la Cordillera Bética puede encontrarse entre 0,1 y 0,3 (Martos-Rosillo et al., 2015), sin embargo, la tendencia de la recarga en acuíferos carbonatados de pequeñas dimensiones localizados en zonas semiáridas es que el coeficiente de infiltración se sitúe más cerca de 0,1 que de 0,3, e incluso con valores inferiores (Martínez-Santos y Andreu, 2010; Aguilera y Murillo, 2009). La variación de la recarga anual con un coeficiente de infiltración de 0,1-0,3 estaría comprendida entre 0,21 y $0,6 \mathrm{hm}^{3} / a n ̃ o$. Esto equivaldría a caudales anuales medios drenados comprendidos entre 7 y $20 \mathrm{l} / \mathrm{s}$.

El valor más elevado es parecido al citado en las primeras etapas de construcción de la galería, $27 \mathrm{l} / \mathrm{s}$, en cambio el segundo es algo inferior a los cerca de $10 \mathrm{l} / \mathrm{s}$ de media estimados en los aforos (Fig. 8). En el primer caso se puede argumentar que los cambios producidos en el clima desde finales del siglo XIX hasta la actualidad han mermado la recarga del acuífero. Se sabe que las temperaturas medias anuales en el mundo han ido subiendo, especialmente a partir de los años 50 y aún más desde los años 80 . El aumento de temperatura incrementa la evapotranspiración y por lo tanto disminuye la recarga. Además, los regímenes pluviométricos han cambiado, especialmente en el sentido de una mayor irregularidad, lo que pue- 


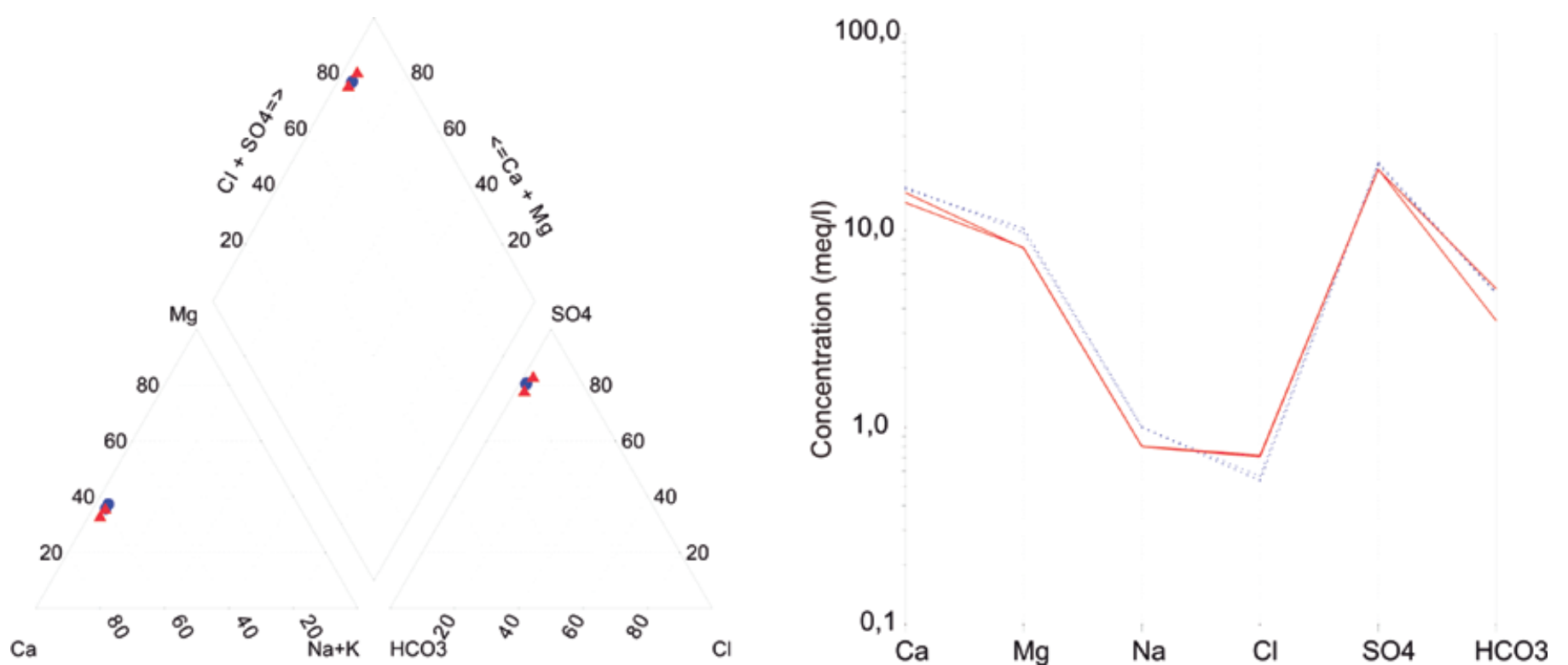

Figura 13. Diagrama de Piper y Shoeller para las muestras analizadas. En rojo las muestras tomadas en 2016 y en azul las tomadas en 2018. Figure 13. Piper and Shoeller diagram. In red, samples taken in 2016 and in blue, samples taken in 2018.

de llevar a una disminución de la recarga por un incremento de la escorrentía superficial.

En el segundo caso, los caudales observados se encuentran ligeramente por encima, lo que puede indicar que posiblemente habría que aplicar un coeficiente de infiltración superior a 0,1.

En agosto de 2018 se realizó un aforo en el interior de la galería en una zona rectilínea, justo aguas abajo de la zona de contacto entre los conglomerados miocenos y los carbonatos triásicos (Fig. 3), el caudal obtenido fue de $14,2 \mathrm{l} / \mathrm{s}$, notablemente superior al obtenido a la salida de la galería. Esto implica que existe una pérdida de caudal desde su nacimiento hasta su salida que puede cifrarse en unos $5 \mathrm{l} / \mathrm{s}$. Esta pérdida es consecuencia de que el nivel freático en el acuífero mioceno se encuentra por debajo de la base de la galería, lo que favorece la infiltración del agua hacia este acuífero. La infiltración, posiblemente también se ve favorecida en las zonas donde hay pequeños embalsamientos por caídas de tierra desde las lumbreras o en el derrumbe que se observa en la lumbrera 6 .

También es posible estudiar el valor de la recarga a partir del valor del cloruro contenido en el agua subterránea, siempre y cuando no existan aportes litológicos de importancia. La metodología es suficientemente conocida y está descrita, por ejemplo, en Custodio y Llamas (1983).

Se dispone de 5 análisis químicos realizados en el agua drenada por la galería (Tabla 1). Los valores del cloruro son ligeramente superiores en las muestras tomadas en 2016 , de 25,1 y $25,6 \mathrm{mg} / \mathrm{l}$, frente a $19-20$ $\mathrm{mg} / \mathrm{l}$ para las muestras tomadas en 2018. El valor medio para la totalidad de las muestras es de $21,7 \mathrm{mg} / \mathrm{l}$. Con estos datos y considerando una precipitación media de $300 \mathrm{~mm}$ anuales y un valor para la deposición del cloruro por el agua de lluvia de $2,5 \mathrm{mg} / \mathrm{l}$ (entre 2 y $3 \mathrm{mg} / \mathrm{l}$ en la zona estudiada según Alcalá y Custodio, 2014) se obtiene un coeficiente de infiltración del 0,115 , lo que equivale a $0,245 \mathrm{hm}^{3} /$ año o $7,8 \mathrm{l} / \mathrm{s}$, valor ligeramente inferior al aforado. Esta diferencia puede deberse a la incertidumbre de los datos utilizados (valor de la deposición del cloruro atmosférico o de la precipitación media) o la existencia de pequeños aportes de cloruro litológico, lo que es posible pues el valor del sulfato es elevado y su procedencia más probable es la disolución de rocas evaporíticas intercaladas en la serie filítica que conforma el sustrato del acuífero. En todo caso el aporte litológico del cloruro necesariamente debe ser de poca importancia. Con la información disponible puede argumentarse que el coeficiente de infiltración podría acotarse entre 0,15 y 0,2.

\section{Hidroquímica}

El elevado valor del sulfato en el agua subterránea implica la existencia de un importante aporte litológico posiblemente debido a la presencia de evaporitas en la formación delTriásico inferior o por la presencia de 

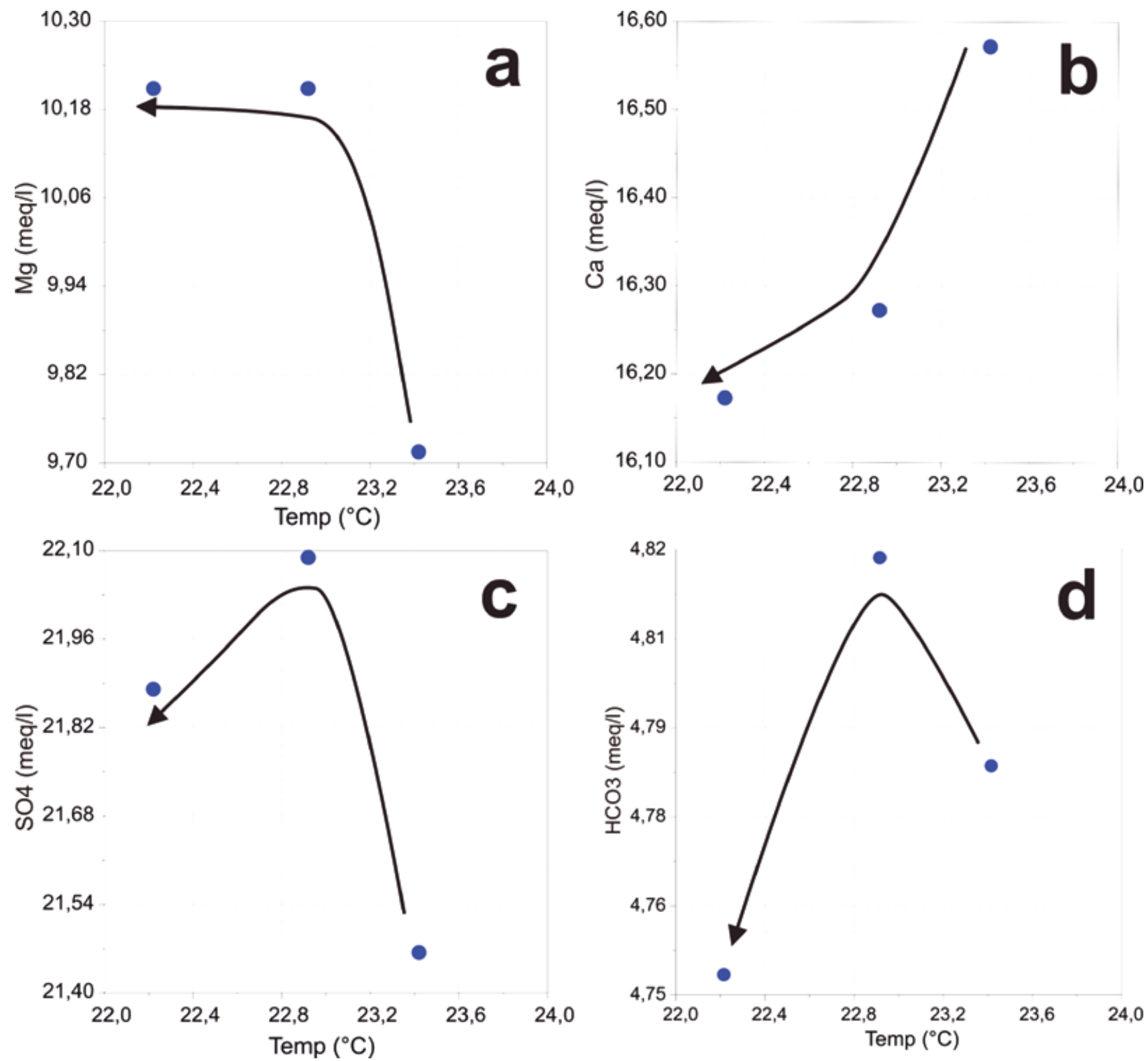

Figura 14. Relación entre la temperatura y los valores de $\mathrm{Mg}^{2+}, \mathrm{Ca}^{2+}, \mathrm{SO}_{4}{ }^{2-}$ y $\mathrm{HCO}_{3}^{-}$para las muestras analizadas en 2018.

Figure 14. Relationships between temperature and $\mathrm{Mg}^{2+}, \mathrm{Ca}^{2+}, \mathrm{SO}_{4}{ }^{2-}$ y $\mathrm{HCO}_{3}^{-}$values for the samples taken in 2018.

yeso reprecipitado en las zonas de fractura, como parece deducirse de los datos aportados por los análisis de 2018 (Fig. 14).

El valor de la temperatura es el mejor indicador de la evolución del agua en la galería, ya que disminuye de forma más o menos lineal desde su nacimiento hasta su salida por la bocamina. En la propia galería, en diversas zonas se ha observado la presencia de precipitaciones de calcita en forma de aceras y de calcita flotante o en el entorno de las propias frac- turas donde se observa su nacimiento (Fig. 12), lo que indica que el agua está sobresaturada en calcita en todo su recorrido. Es de esperar que exista una disminución del calcio y del bicarbonato en el agua desde el nacimiento hasta su salida por la bocamina como consecuencia de esto. Si bien los valores son similares en todas las muestras, de un análisis más detallado se pueden observar algunos procesos que merecen ser destacados. El diagrama de la figura 14b muestra una disminución del Ca congruente con lo 
anterior, sin embargo, esta disminución no es lineal. En cambio, el valor del $\mathrm{HCO}_{3}^{-}$muestra un incremento desde su nacimiento hasta la zona intermedia y una posterior disminución (Fig. 14d).

Con el $\mathrm{SO}_{4}^{2-}$ ocurre algo similar, aunque con una disminución final más suave. Esto solo puede explicarse por la existencia de nuevos aportes de agua más mineralizada localizados entre el punto de muestreo CJ3 y el CJ2, que podría estar relacionada con la zona intensamente fracturada que pone en contacto los conglomerados miocenos con los carbonatos triásicos. Este agua, más mineralizada, presentaría mayor contenido en $\mathrm{SO}_{4}{ }^{2-}, \mathrm{HCO}_{3}{ }^{-}$y $\mathrm{Mg}^{2+}$, como se observa en los diagramas de la figura $14 a, c y d$. Un mayor aporte de $\mathrm{Ca}$, provocaría la inmediata precipitación de calcita por efecto ion común. Más difícil es explicar la disminución del $\mathrm{SO}_{4}{ }^{2-}$, que, aunque pequeña, es significativa. Tal vez podría explicarse por la presencia de abundante materia orgánica relacionada con el guano de la colonia de murciélagos que habita permanentemente la galería. La cálida temperatura existente durante todo el año por la existencia de termalismo la hace ideal para el refugio de los quirópteros. La presencia del guano podría provocar la reducción de parte del sulfato con la consiguiente disminución de su contenido en la parte final de la galería. La existencia de precipitados blancos que recubren las paredes de la galería en algunas zonas (Fig. 12d) que podrían ser de yeso, tal vez esté relacionada con procesos de reducción de una pequeña parte del sulfato con emisión de gas sulfhídrico que a su vez provocaría la precipitación de yeso en las paredes de la galería, si bien esta posibilidad está aún pendiente de investigación.

\section{Conclusiones}

La galería del Cabezo de la Jara fue construida entre los años 1864 y 1866 y reconstruida dos veces más a cotas menores debido a la rivalidad por la captación del agua con los regantes del vecino término municipal de Puerto Lumbreras (Murcia). La obra final acabó en 1886 con una galería de más de $2 \mathrm{~km}$ de longitud donde se localizan tres entradas y 15 lumbreras y al menos una lumbrera más un poco alejada de la traza. Posteriormente, fue modificada eliminando el paso por un tramo. Su longitud actual es de $1468 \mathrm{~m}$, con un desnivel entre la Entrada 1 y el final de la galería de tan solo $1 \mathrm{~m}$. La diferencia de cota entre la boca y el punto más alto medido, en la lumbrera más profunda, fue de $63 \mathrm{~m}$.

La galería está excavada en su mayor parte en conglomerados poligénicos del Mioceno Superior, corta el acuífero formado por carbonatos triásicos a una distancia de $850 \mathrm{~m}$ desde la Entrada 1 y previamente atraviesa una franja brechificada de $15 \mathrm{~m}$ de espesor; en estos dos últimos tramos es donde se produce la ganancia de agua. Actualmente la galería es el refugio de una numerosa colonia de murciélagos de la especie Myotis Myotis (murciélago ratonero grande).

El acuífero drenado presenta una estructura compleja, sus afloramientos permeables tienen una superficie de $7 \mathrm{~km}^{2}$ y necesariamente deben estar hidráulicamente conectados entre sí, pues solo así puede explicarse el caudal drenado por la galería. Todos sus bordes están formados por filitas de baja permeabilidad excepto el límite sur y suroriental donde los carbonatos están recubiertos por los conglomerados miocenos. Precisamente en este borde existen varios depósitos de travertinos que indican una antigua posición de la descarga natural del acuífero. Dos de esos depósitos son explotados actualmente como cantera de roca ornamental.

El caudal de descarga fue estudiado a partir de aforos realizados entre 2015 y 2018 con una media de $9,4 \mathrm{l} / \mathrm{s}$, sin embargo, aforos diferenciales realizados en la salida de la galería e inmediatamente antes de las áreas de surgencia en el interior de la galería mostraron una posible pérdida de caudal de unos 5 I/s que se infiltrarían en los materiales detríticos.

De la información disponible se deduce que los recursos medios del acuífero podrían estar comprendidos entre 0,3 y $0,4 \mathrm{hm}^{3}$ anuales con un Coeficiente de Infiltración entre 0,15 y 0,2.

El agua drenada por la galería presenta una temperatura unos $6^{\circ} \mathrm{C}$ más elevada que la temperatura media anual de la zona, lo que indica que hay hipotermalismo. La temperatura del agua es de $23,4^{\circ} \mathrm{C}$ en su zona de surgencia en el interior de la galería. EI agua es de facies sulfatada cálcico magnésica con unos $1000 \mathrm{mg} / \mathrm{l}$ de $\mathrm{SO}_{4}{ }^{2-}$ y bajos valores de $\mathrm{Cl}^{-}$. La CE está comprendida entre 1937 y $1961 \mu \mathrm{S} / \mathrm{cm}$. El agua presenta condiciones incrustantes en todo su recorrido, con precipitados de carbonato cálcico en forma de calcita flotante y aceras. También es posible la existencia de precipitados de yeso recubriendo algunas zonas de las paredes. De la evolución del quimismo del agua en la galería se deduce la probable presencia de descargas de aguas, ligeramente más mineralizadas, a través de la zona de fractura que pone en contacto los carbonatos triásicos y los conglomerados miocenos.

La galería del Cabezo de la Jara es uno de los principales y mejor conservados ejemplos de qanat de la provincia de Almería. Los conflictos generados tras el alumbramiento del agua, por si solos, ponen de manifiesto la importancia de estos escasos recursos en la zona. La galería es actualmente el principal pun- 
to de interés hidrogeológico de la comarca de Huércal Overa y la descarga de mayor caudal existente en el término municipal. Tanto las técnicas que llevaron a su construcción en el siglo XIX, como las singulares características hidrogeológicas del acuífero con el que se relaciona e hidroquímicas del agua, hacen que la galería cobre un interés histórico y científico de primer orden. Por otra parte, las pequeñas dimensiones del acuífero carbonatado triásico y su escasa recarga, ponen de manifiesto la fragilidad del mantenimiento de la descarga, ya que cualquier bombeo, mediante sondeo, que se realice en el mismo podría ocasionar la desecación de la descarga. Por este motivo, urge la declaración de un perímetro de protección enfocado a la conservación de la galería y su declaración como punto de interés histórico singular.

Otro tema de especial interés es la colonia de murciélagos que alberga que, debido al hipotermalismo existente, encuentra unas condiciones ideales para su utilización durante todo el año. Por esta razón, deben también establecerse medidas enfocadas a la conservación de estas colonias, impidiendo que los puntos de entrada y salida de los quirópteros a la galería sean taponados y que se restrinjan las visitas de tipo "turístico", que por otra parte pueden ser peligrosas para la integridad física de quienes las realicen.

\section{Agradecimientos}

Este trabajo es una contribución a la Red CYTED P419RT0577 "Siembra y Cosecha del Agua en Áreas Naturales Protegidas". Nuestro agradecimiento a Tomás Rodríguez Estrella y Ramón Aragón Rueda por sus constructivas revisiones que han contribuido a mejorar este trabajo.

\section{Referencias}

Aguilera, H. and Murillo, J.M. 2009. The effect of possible climate change on natural groundwater recharge based on a simple model: a study of four karstic aquifers in SE Spain. Environmental Geology 57, 963-974.

Alcalá, F. J. and Custodio, E. 2014. Spatial average aquifer recharge through atmospheric chloride mass balance and its uncertainty in continental Spain. Hydrological Processes, 28(2), 218-236.

CHG 1995. Informe parcial $n^{\circ} 1$. Caracterización hidrogeológica de los acuífero y criterios a utilizar en la selección de puntos. Proyecto para la instalación, mantenimiento y operación de redes oficiales de control de las aguas subterráneas. Piezometría, hidrometría y calidad. Cuenca del Segura. Informe interno.

Corvi, M.TopoDroid-SpeleoApps [Internet]. [cited 2019 May 21]. Available from: https://sites.google.com/site/speleoapps/home/topodroid

Custodio and Llamas, 1983. Hidrología subterránea. Ed. Omega (2 ${ }^{\mathrm{a}}$ edición). 2Tomos, Barcelona, 2350 pp.

García Asensio, E. 1910. Historia de la Villa de Huércal Overa y su comarca.

Gil Meseguer, E. and Gómez Espín, J. M. 2016. Las aguas de fuentes en Huércal-Overa (Almería). El modelo de la sociedad colectiva de aguas titulada "La Asunción". Libro Jubilar en homenaje al profesor Antonio Gil Olcina. Instituto Interuniversitario de Geografía Universidad De Alicante, 215-230.

Gil Meseguer, E.; Martínez Medina, R. and Gómez Espín, J.M. 2009. El Cabezo de la Jara: un relieve de la frontera murciano-almeriense. Papeles de Geografía, 49-50, 6982.

Heeb, Beat. Paperless Cave Surveying [Internet]. [cited 2019 May 21]. Available from: http://paperless.bheeb.ch/.

IGME 1996. Nota técnica en relación a la posible afección de los trabajos que se realizan en la cantera Gaona sobre los manantiales y la galería de agua propiedad de la Sociedad de Aguas la Asunción. Huércal Overa (Almería). Informe interno. (http://info.igme.es/ConsultaSID/Index. asp).

IGME 2010. Identificación y caracterización de la interrelación que se presenta entre aguas subterráneas, cursos fluviales, descarga por manantiales, zonas húmedas y otros ecosistemas naturales de especial interés hídrico. Masa de agua subterránea 071.059 Enmedio-Cabezo de Jara. Encomienda de gestión para la realización de trabajos científico-técnicos de apoyo a la sostenibilidad y protección de las aguas subterráneas. Dirección General del Agua, Ministerio de Medio Ambiente y Medio Rural y Marino.

Martínez-Santos, P. and Andreu, J.M., 2010. Lumped and distributed approaches to model natural recharge in semiarid karst aquifers. Journal of Hydrology 388, 389-398

Martos-Rosillo, S., González-Ramón, A., Jiménez-Gavilán, P., Andreo, B., Durán, J. J., and Mancera, E. 2015. Review on groundwater recharge in carbonate aquifers from SW Mediterranean (Betic Cordillera, S Spain). Environmental Earth Sciences, 74(12), 7571-7581.

Voermans, M., Geel, T. and Baena Pérez, J. 1979. Memoria y mapa geológico. Hoja 974 Vélez Rubio E. 1:50.000. IGME.

Recibido: julio 2019

Revisado: noviembre 2019

Aceptado: enero 2020

Publicado: marzo 2021 